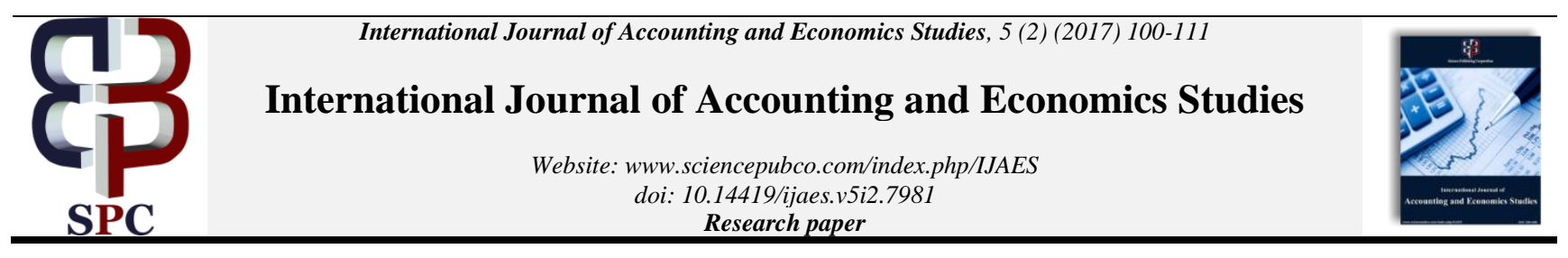

\title{
The role of resistance in incorporating XBRL into financial reporting practices
}

\author{
Adam Krisko * \\ Department of Social Sciences and Business, Roskilde University, Universitetsvej 1, Building 23.1, 4000 Roskilde, Denmark \\ *Corresponding author E-mail: krisko@ruc.dk
}

\begin{abstract}
Using the actor-network theory (ANT), this article sought to analyze the translation process induced by the Danish regulatory agency for financial reporting to incorporate the eXtensible Business Reporting Language (XBRL) into the financial reporting practices, giving special attention to how resistance demonstrated by certain actors shapes the process of incorporating the technology into the financial reporting environment. The empirical analysis, relying on a series of semi-structured interviews conducted between November 2013 and February 2016, highlighted the strategic steps taken by the regulatory agency to deal with the emerging resistance. The analysis illustrated how the initial setting created at the early stages of the translation process develops into a socio-technical context in which the participating actors' no longer express resistance, and commit to the incorporation of XBRL. In this respect, the paper contributes to previous studies on XBRL, adds to the financial reporting literature by illustrating how resistance shapes the introduction of complex regulatory changes, and contributes to the ANT literature, especially those based on Michel Callon's translation model.
\end{abstract}

Keywords: Accounting Environment; Actor-Network Theory; Financial Reporting Regulation; Translation; XBRL.

\section{Introduction}

The demand for utilizing technological developments in order to improve the efficiency of financial reporting, and thus preventing the occurrence of accounting fraud such as in the cases of Enron, WorldCom or Lehmann Brothers, has been increasingly growing ever since the beginning of the 2000s. One of these technological developments is the eXtensible Business Reporting Language (XBRL), an Extensible Markup Language (XML) based, open standard, free of license fee's electronic language for recording, processing and communicating business information. Since its creation by Charles Hoffman in 1998, XBRL-and especially the utilization of it - has gone through a remarkable development which resulted in XBRL being put to practical use in a number of countries as part of the financial reporting practices (Müller-Wickop et al.2012).Storing the financial data in XBRL format enables it to be machine-readable, and standardizes the financial terms through XBRL taxonomy thus enabling 'meaningful comparison of financial information across businesses and allows for the aggregation of financial information across a business sector for monitoring purposes' (Chen 2012, p. 554).These attributes have made XBRL rather appealing for both financial and management accounting practitioners, and regulators within the financial reporting environment. Researchers expect XBRL to develop into the global data standard for business financial reporting in the near future (Liu et al. 2014). The expansion of the practical utilization of XBRL has also drawn attention from business, market and academic sectors, and inspired research in various fields of accounting and auditing. For instance, financial accounting scholars have explored the qualitative characteristics of XBRL thus assessing whether the technology can be capable of delegating certain mechanisms into the financial reporting practices that potentially contribute to improvement (e.g. Baldwin et al. 2006, Branson 2002, Chang \& Jarvenpaa 2005, Chen 2012, Cohen et al. 2014, Debreceny et al. 2011, Efendi et al. 2014, Liu et al. 2014a, Liu et al. 2014, Plumlee \& Plumlee 2008, Srivastava \& Kogan 2010, Venkatesh \& Armitage 2012, Zhu \& Wu 2014).

Another stream of research has been focusing on the possible utilization of XBRL within organizational settings (e.g. Alles \& Piechocki 2010, Bartley et al. 2011, Chowdhuri et al. 2014, Doolin 2007, Gray \& Miller 2009, Henderson et al. 2012; Troshani et al. 2011). Despite XBRL having been established as the obligatory electronic format of financial reporting in numerous countries - including the United States, the United Kingdom, China, France, Japan, and Denmark - the process of incorporating XBRL into the financial reporting practices on the national level has been empirically examined in only a few studies (e.g. Chen 2012, Troshani 2010). Literature suggests that the establishment of XBRL demands significant effort, such as acquiring relevant knowledge - accounting personnel needs to be trained- and establishing necessary IT infrastructure (Bartley et al. 2011, Doolin \& Troshani 2007) on the organizational level, but empirical evidence on the efforts at the national level is rare. The purpose of this paper was to address this gap in the literature and seek an answer to the following question: how does XBRL get incorporated into the financial reporting environment of a country?

The incorporation of a technology - in this case XBRL - into an existing environment requires certain changes that might be against the will or beyond the capabilities of actors within that particular environment. This can lead to the emergence of resistance to change faced by the actors who are willing to incorporate the technology. The particular aim of this paper was to analyze how the process of incorporating XBRL is shaped by the interaction between the actors within the financial reporting environment, while focusing on the role of resistance in shaping the above process. 
To provide a framework to the analysis, the actor-network theory (ANT) and more specifically the translation model developed by Michel Callon (1986) are introduced. The rationale behind the application of ANT is that it offers a framework for exploring the introduction of a technology into a certain environment. According to ANT, this process is considered to be a series of dynamic interactions between attempts to cause a change and reactions to avoid change. These reactions are responses to certain controversial elements of the incorporation of the technology that represent resistance, and are articulated by the participating actors who do not wish to or simply cannot agree with certain steps towards the introduction of the technology. The enunciator - the actor inducing the process of introducing the technology - needs to respond to and deal with this resistance in order for the technology to become a durable part of the already existing environment it is incorporated into. The word 'resistance' in this context refers to both the active (the refusal to accept or comply with something) and passive (the ability not to be affected by something) implications of the term. As such, resistance is considered to be generated by both human and non-human actors against some particular aspects or the entire process of incorporating a technology into an existing environment The reason behind using the term 'incorporation' in the research question of this paper is that it refers to the process of making something part of an already existing whole. One might argue that other terms, such as 'implementation' or 'adaptation' could be used as well, but those concepts might generate confusion at such an early stage of the study. 'Implementation' might suggest that the introduced technology remains unchanged during the process of incorporation, while 'adaptation' might imply a process of change. The nature of the types of change is unclear at this point in this paper, therefore the term 'incorporation' seems to be more adequate. The analytical framework was applied to the efforts of the regulatory agency for financial reporting in Denmark to incorporate XBRL into the Danish financial reporting environment. At various stages, this process became controversial and contested by certain actors. The exploration of such episodes enabled analyzing the role of resistance in shaping the incorporation of XBRL into the financial reporting environment.

The paper contributes to three streams of literature: first, it adds to the XBRL literature by showing how XBRL is incorporated into the financial reporting system on a country. Secondly, it adds to the financial reporting literature by illustrating how resistance shapes the introduction of certain changes - such as a technology aiming to improve regulatory surveillance - within the financial reporting environment, and how regulators deal with resistance within the financial reporting environment when introducing complex changes like XBRL. Thirdly, the paper adds to the ANT literature - especially those based on Callon's (1986) translation model - by illustrating how the emerging resistance creates certain situations in which the actors need to reconsider their strategies during the process of translation.

The rest of the paper is organized as follows. The second chapter reviews prior research concerning the role of resistance in shaping financial reporting regulation and subsequently introduces the translation model along with a discussion about how it is used in relation with the subject of this paper. Chapter 3 introduces the research strategy by presenting the methods of data collection and analysis. The discussion of the main methodological considerations is followed by an empirical chapter presenting the story of incorporating XBRL into the Danish financial reporting practices and analyzing the emerging resistance during the incorporation process. Chapter 5 concludes the paper by drawing conclusions and wrapping up the findings of the research.

\section{Researching the role of resistance in shaping financial reporting regulation}

\subsection{Resistance and the interaction between actors in the} financial reporting regulatory environment
As Baudot and Walton (2014) demonstrated, the majority of research has theorized about the interaction between the actors participating in the regulatory processes of accounting from the standpoint of classical economic and regulatory theory. Studies such as Laffont and Tirole (1993), Peltzman (1976), Sutton (1984) or Watts and Zimmerman (1978) attempted to explain these processes built on the economics of regulation theory (Downs 1957, Stigler 1971) and assumed that the actors participating in the regulatory processes express rational and self-interested behavior based on clearly defined preferences and interests. In such scenarios, the actors are portrayed as being aware of the nature of the proposed change in the regulatory environment, capable of measuring the expected benefits from the changes and making rational decisions based on those measurements. In case the expected cost of the regulatory change exceeds its expected benefits the concerned actor expresses resistance against the proposed change and tries to influence it.

Further research aiming to explain the regulatory processes of accounting led to the emergence of a stream of literature focusing on the struggle between the interests of the regulators and certain actors of the accounting environment. Important contributions to understanding how actors demonstrate resistance through lobbying against decisions made by regulatory agencies and legislators were provided by studies such as Georgiou (2002), Hill, Shelton and Stevens (2002), Kelly (1982, 1985) and Kenny and Larson (1993). Most of these studies took an institutional theoretic approach and focused on the strategic choices made by organizations as the basis of calculating the costs and benefits of lobbying.

Studies such as Fogarty, Hussein and Ketz (1994), Jönsson (1994), Power (1993) or Sikka (2002) added important contributions to the literature on the political aspects of financial accounting regulation, while illustrations of how regulatory processes of accounting and auditing can generate controversies and thus resistance to change were provided by Becker, Jagalla and Skærbæk (2014), Hoffmann and Zülch (2014), Jeppesen (2010), Jorissen, Lybaert, Orens, and van der Tas (2012), and Malsch and Gendron (2011).These studies illustrated how changes in accounting and auditing practices introduced through regulation can induce certain dynamic relationships that set up particular challenges for various actors as they need to respond to several interessement devices that are used to enroll them into the new practices established by the change in the regulatory environment. One of the few empirical studies analyzing the process of incorporating XBRL into a country's regulatory framework for financial reporting was conducted by Troshani and Lymer (2010). The study highlighted the critical role of focal actors in achieving effective translations in technology standardization, and suggested that separating the technical from the social by considering the introduction of XBRL into a certain financial reporting environment merely as a technical issue can lead to controversies and resistance. The importance of enrolling the social side, especially actors representing accounting professionals, in the process of introducing regulatory changes was also shown by Becker et al. (2014), illustrating that the lack of enrollment might lead to serious project stagnancy and 'strategies of total resistance'.

The accounting literature suggests that resistance demonstrated by the actors within the financial reporting environment plays an important role in shaping the overall process of financial accounting regulation. Studies illustrating the regulatory processes have tended to assume that resistance emerges due to the actions of the participating actors within the regulatory environment, and these actions are based on the preferences and interests among the actors. Such scenarios suggest that the actors are aware of both the nature of the regulatory change and their own interests when demonstrating resistance to change. In order to deal with the emerging resistance, the regulators need to take strategic steps thus removing the barriers of introducing changes into the financial reporting environment. This paper takes up the suggestions of Callon (1986) by developing an ANT-based approach to explore the role of resistance in incorporating a certain technology - in this case XBRL - into the financial reporting practices. 


\subsection{The ANT perspective on the incorporation of tech- nologies}

ANT suggests that the incorporation of a technology into an already existing environment should be regarded as a translation through which an actor attempts to cause a change by introducing the technology, which is achieved by successfully transforming the will of other actors into a single will (Callon \& Latour 1981). This is needed to transform the will of other actors simply because they are not always aligned with the will of the actor attempting to introduce the technology, which can generate resistance. As such, the translation process is characterized by the constant interaction between programs of action - the attempt to cause a change - and reactions to avoid change.

According to Callon (1986), the translation is divided into four phases: 1) problematization, 2) interests, 3) enrollment and 4) mobilization. Problematization is a process during which the enunciator of the program of action sets the establishment of the technology into motion by formulating a goal, inter defining the actors needed to find a way to achieve this goal, and defining an obligatory passage point all the actors need to pass in order to reach their own goals. The program of action is regarded as the enunciator's attempt to cause a change. Callon emphasized the hypothetical aspect of the problematization, since at this point 'the entities identified and the relationships envisaged have not yet been tested. The scene is set for a series of trials of strength whose outcome will determine the solidity of the problematization' (Callon 1986, p. 201). The first trials of the strength of the problematization occur during the process of interessement, when the enunciator attempts to impose and stabilize the identity of the other actors it has defined through the problematization. Each actor can either approve the predefined role in the initial plan, or decide to take a reaction against the program of action, thus generating resistance. If the program articulated by the enunciator is to become durable it needs to adapt to the emerging resistance by responding to the reactions (Latour 1991, p. 105). The interessement is followed by the process of enrollment, during which the actors apply a group of multilateral negotiations, trials of strength and tricks to enroll the other actors into the process of working toward reaching their goals. During enrollment 'a set of interrelated roles is defined and attributed to actants who accept them' (Callon 1986, p. 205). Finally, enrollment needs to be turned into active support from the participating actors. This occurs through the process of mobilization, during which the designated representatives of the actors render the entities they represent mobile in order to complete the translation and establish the technology.

Callon's theoretical model emphasizes the central role of the enunciator during the translation: it is, in fact, the enunciator's actions attempting to cause change that leads to the emergence of controversies and eventually resistance (to change). In Callon's terminology, controversies refer to all the manifestations and occurrences of episodes during which the actions taken to realize the program of action are questioned, discussed, negotiated and rejected (Callon 1986, p. 210). Due to these controversies, and the emergence of resistance demonstrated by participating actors, the original program of action goes through transformation, thus shaping the incorporation of the technology into an already existing environment.

\subsection{Accounting research and ANT}

Since the early 1990s, ANT has had an important impact upon accounting research by inspiring a number of innovative studies of accounting phenomena (Justesen \& Mouritsen 2011). ANT has provided researchers with a theoretical toolbox that enables the illustration of how certain changes occur within the realms of accounting through the development of actor-networks. Miller (1991) argued that prior to ANT, accounting researchers tended to take contingency or institutionalist approaches and explain accounting change concerning a stable set of external variables. On the other hand, ANT regards accounting change as a series of historical processes initiated by the interaction between heterogeneous actors within the accounting environment. Studies such as Becker et al. (2014), Briers and Chua (2001),Preston, Cooper and Coombs (1992), and Robson (1991)argued that successful introduction of changes into accounting systems demands that the initial interests of the participating actors are reconfigured and channeled in specific directions. Such reconfiguration and redirection of interests within the emerging actor-network imply that the process of introducing accounting change does not simply occur through diffusion, adaptation or implementation, but rather through translation. Once the process of translation is completed the introduced change becomes part of the accounting environment and enables certain actions that were not possible before the translation (Robson 1992).

\section{Research methodology}

As discussed earlier in this paper, XBRL is considered a technology introduced through translation. In order to reconstruct the process of translation while XBRL is incorporated into the financial reporting environment within a specific financial reporting environment, namely Denmark, 26 people participated in a series of semi-structured interviews between November 2013 and February 2015, and a focus-group interview in February 2016.

The interviewee-selection was not pre-determined at the beginning of the data collection: the analysis of the first interviews conducted in late 2013 induced the process of laying out the significant events and mapping the important actors of the case, thus identifying further interviewees. All in all, the primary data was collected from current and previous senior consultants and heads of sections at the Danish Business Authority (previously DCCA), senior consultants of FSR - Federation of Danish Auditors, owners and IT personnel of software developer firms, partners and auditors of the Big Four auditor firms, board members of XBRL Denmark, managers and analysts of financial institutions; representatives of Danish state authorized public accountancy firms, and independent accounting professionals. The individual interviews were based on semi-structured interview design: an interview guide was prepared for each interview consisting of an informal grouping of topics and questions to be explored. The interview guide was sent to the interviewees a couple of business days prior to the interviews. Although the interview guide provided a frame for the interviews, new ideas were allowed to be brought up during the sessions by the interviewees. Furthermore, the questions asked were open rather than closedended questions in order to have participants use their own words instead of predefined ones during the discussions. The interviews were conducted through personal meetings with the interviewees. The sessions were recorded by the voice-recorder. The text was then transcribed, and the relevant information was systematically organized and finally incorporated in the text of the paper. In order to gather more relevant data for the analysis, a focus group interview was conducted at the XBRL Denmark board meeting in February 2016: the initial findings of the paper were presented - along with the theoretical considerations of the research - to the members of the board, which then was followed by a one-hour discussion with all the participating individuals sharing their opinion and ideas. The gathered primary data aimed to reconstruct the process of incorporating XBRL into the Danish financial reporting practices. It is important to mention that the illustration of the translation process does not intend to cover the incorporation of the technology at the organizational level. As such, the empirical analysis remained at the national level and the story presented in this paper ends once $\mathrm{XBRL}$ is incorporated into the Danish regulatory framework for financial reporting.

To analyze the collected data Latour's (1991) suggestions were applied. As discussed earlier, the original program of action articulated by the enunciator goes through change - due to the resistance demonstrated by the participating actors - and changes itself before it gets incorporated and thus embedded within society. Latour emphasized that in order to explore the process of translation the researcher 'needs to follow the simultaneous production of a text and the context, by keeping track of the successive changes undergone 
by the different actants participating in the process' (Latour1991, $\mathrm{p}$ 105-106). Thus the collected empirical data is organized in a way that allows for the illustration of the successive changes of both the program of action and the participating actors. This is done by focusing on the resistance emerging during the translation process, and the actions taken in order to resolve the resistance. Another important thing to emphasize in relation to the methodology of this paper concerns the epistemological and ontological considerations: the underlying processes of translation within a financial reporting environment would be difficult to interpret in terms of a single, fixed reality. Therefore, the illustration of the case follows an interpretivist approach thus assuming that reality is relative and multiple (Hudson \& Ozanne 1988). This approach enables the representation of the different interpretations of the occurring changes demonstrated by the actors, thus exploring how these different interpretations lead to the emergence of resistance, the actions aiming to resolve the resistance and eventually complete the translation process.

\section{The story of incorporating XBRL into the Danish financial reporting environment}

\subsection{The processes of problematization and interessement}

\subsubsection{The definition of the initial program of action and the par- ticipating actants}

The thought of implementing mandatory digital financial reporting in Denmark has a rather long history. The idea began to take shape when the regulatory agency responsible for the surveillance of financial reports in Denmark, the Danish Commerce and Companies Agency (DCCA), in the middle of the 1980s expressed their motivation to utilize information technology for developing a digital financial reporting system throughout the country and as such replacing the existing paper-based system. Digitization was considered an obvious next step to improve the existing financial reporting practices by utilizing the advances offered by information technology (IT). As such, digitization was not the goal itself, but rather a tool to achieve the goal of establishing certain improvements through digitization. As one of the managers of the project at the DCCA stated:

"Scientific research suggested that efficiency could be improved through digitization - and the intention to improve ef ficiency of the existing financial reporting procedure was the key driver behind the project." (Project manager at DCCA)

Improved efficiency was realized in the forms of simplified administrative burdens, higher compliance due to the increasing quality of the disclosed financial data, and increasing efficiency of information flow due to better data handling and processing. As another project manager at the DCCA argued:

"Achieving higher compliance was definitely one of the main purposes of the project. With such a [digitized] system it becomes easier to make people and companies follow the law. ... A reporting system based on machine-readable financial data makes it easier to find the unintentional errors in the financial statements. Furthermore, computer assistance can help handling issues needing more sophisticated control mechanisms, such as corporate fraud." (Project manager at DCCA)

At the beginning of the 2000's the DCCA decided to start taking explicit action to digitize the Danish financial reporting system. In this certain setting, the DCCA played the role of the enunciator, and the emergence of its intention to establish improvements within the existing financial reporting environment through digitization led to the articulation of the original program of action. In order to induce a successful translation process, the DCCA first needed to determine the participating actors and define their identities in relation to the introduction of digitization into the financial reporting practices. First, the intention of the DCCA was to build the digitized system only with the help of IT professionals. A project leader at the DCCA, who used to work for the agency at the beginning of the 2000s and actively participated in the project that time, pointed out:
"At the beginning, the plan was to work in the project without involving any actors besides some IT professionals who would help build the system. However, we [the project leaders at the DCCA] later realized that other key parties were needed to be involved if we were to successfully build the new financial re- porting system." (Project manager at DCCA)

One of these key parties was the group of business enterprises operating within the Danish jurisdiction: it was the actor representing the source of the financial data within the financial reporting supply chain therefore they were assumed to be influenced significantly by the digitization. The DCCA assumed that if the enterprises could be convinced about the potential benefits of the digitization, then the establishment of a digital financial reporting system would receive significant support.

Another actor believed to have the potential to develop into a key player during the translation process were the intermediaries within the financial reporting supply chain, namely the accounting professionals turning the data into useful information. The accounting professionals - bookkeepers, the preparers and auditors of the financial statements, such as professionals working for the Big Four or smaller accounting firms, directors of business entities who are qualified for preparing financial statements and individual accounting professionals - were considered to be one of the primary users of the digitized financial reporting system. A project manager at the DCCA stated:

"Ever since the beginning of the project it was obvious that we [the DCCA] would have to convince the accountants and auditors to actually use the digitized financial reporting system once it was ready. Although at the earlier stages during the project, the accounting professionals were not expected to participate actively in the creation of the new system." (Project manager at DCCA)

As previously mentioned, the problematization and the enunciation of the program of action demanded the involvement of another actor as well, namely the group of IT professionals who would assist the DCCA in designing and developing the IT infrastructure of the new system.

As such, the actors initially considered by the regulatory agency as key players of the upcoming translation process were the following: the business enterprises operating within the Danish jurisdiction, the accounting professionals and the IT-professionals.

\subsubsection{The definition of obligatory passage point}

After defining the actors needed to introduce digitization into the financial reporting practices the DCCA needed to establish an obligatory passage point in order to demonstrate that the interests of these actors lie in accepting the proposed program of action. As one of the managers of the project at the DCCA stated:

\footnotetext{
"We needed to emphasize that digitization would be beneficial for all the main actors within the financial reporting environment, and that there was an actual demand for digitization. We argued that this demand was driven by the need for being able to go through more numbers [within the disclosed financial statements] which would contribute to a more transparent and more efficient economy in the long run." (Project manager at DCCA)
}

The initial program of action suggested that the obligatory passage point of the translation process would be digitization, which was also present in the rhetoric used by the DCCA to involve the key 
actors in the translation process. The regulators argued that business enterprises would be able to decrease their financial reporting related expenses in the long run - which would contribute to their intention of maximizing economic profit. As one of the project leaders at the DCCA pointed out:

"We assumed that the implementation of digital financial reporting would demand certain expenses from the business enterprises, such as building the necessary IT infrastructure inside the organization and training of personnel. Therefore, we [the DCCA] needed to emphasize the long-term benefits from the project, and argue that these investments would allow the automation of certain processes along the financial reporting supply chain, which would decrease the costs of financial reporting in the long run." (Project manager at DCCA)

The accounting professionals were also among the actors considered to be able to realize certain benefits through the digitization of the Danish reporting system. The DCCA argued that digitization would allow the accounting professionals to improve their professional knowledge and skills, and develop them to a level to ensure that their clients or employers receive competent professional services based on developments in accounting practice and techniques. Digitization was also considered to help the accounting professionals get rid of the paper-based, analogue practices, and enable them to incorporate automation into their processes. According to a project leader at the DCCA:

"We supposed that there would be some resistance demonstrated by the auditors [and other accounting professionals] against the new system, because it might appear as an externa force that makes them change their "old, well-functioning" practices. Nevertheless, we hoped that realizing the potential benefits of digitizing their practices would convince them that this was actually a good thing." (Project manager at DCCA).

The third actor the enunciators endowed with a key role during the translation process were the IT professionals, who - at the beginning of the project - were the only actor besides the DCCA that was expected to demonstrate active participation. The IT professionals were expected to be able to deal with the lack of knowledge regarding how the existing IT infrastructure needed be developed to create a digitized financial reporting system in which the Danish financial reporting taxonomy is weaved together with a well-functioning and stabile IT platform. The IT professionals were considered to be able to realize scientific achievements and monetary profit by contributing to the process of building a digitized financial reporting system.

After having established digitization as an obligatory passage point within the network of actors, the DCCA was building the project leaders at the regulatory agency and decided to further strengthen the obligatory passage point by proposing a specific technology to build the digitized system upon. Finding a technology was considered necessary for being able to build a solid argument and offer the promise of a feasible implementation strategy. The role of XBRL as the obligatory passage point was not obvious at the time of defining the program of action. The first attempts to assess the possibility of establishing a digitized system were based on the EDIFACT (Electronic Data Interchange for Administration Commerce and Transport) standards, before the agency's attention shifted toward experimenting with the usage of XBRL at the beginning of the 2000s. The idea of using XBRL for financial reporting purposes emerged after the world's leading companies for auditing, financial systems and electronic communication had expressed a determined intention to develop XBRL into a new standard for digital accounting data (Henriksen 2001). The main motivation of the companies was to use the technological development for improving their managerial accounting and analytical practices, but regulatory agencies all around the world - especially in Australia, England and the United States - quickly recognized the potential of the technology as well (Horn 2004). The possible benefits of XBRL as a technology that can be used for financial reporting purposes were further advertised at the first XBRL International meeting in London, February 2001, which convinced the DCCA to establish XBRL as an obligatory passage point during the process of translation. As one of the project leaders at the DCCA stated:

"Academic research suggested that financial data stored in XBRL format can provide better quality data for analysts, investors and other people digging into the annual reports on a more sophisticated level.” (Project manager at DCCA)

Actor
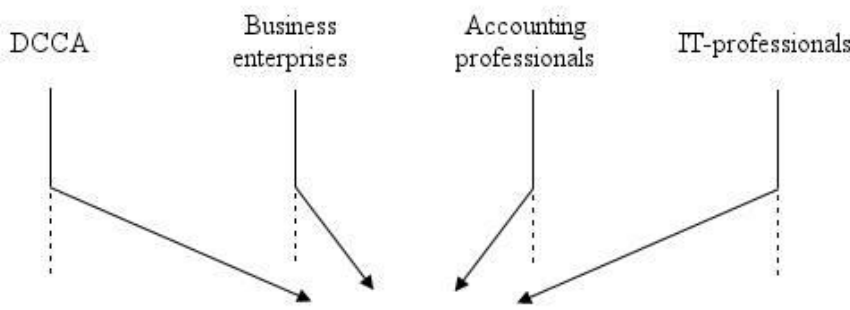

Obligatory Passage Point

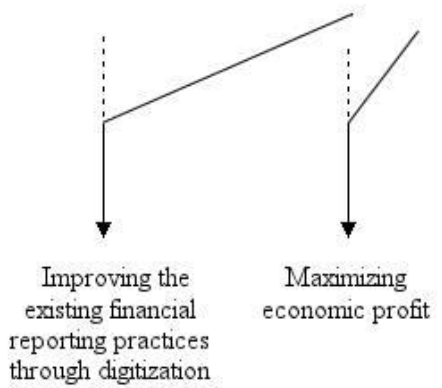

XBRL

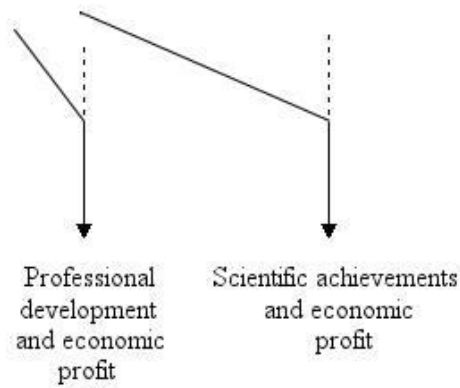

Fig. 1: The Problematization proposed by the DCCA with XBRL as the Obligatory Passage Point. 
Figure 1 illustrates the problematization proposed by the DCCA with XBRL as the obligatory passage point, and how the actors participating in the translation process were considered by the regulators to be able to achieve their goals through XBRL. It is important to emphasize that Figure 1 illustrates the problematization from the DCCA's point of view: the 'goals of the actors in the figure above are the result of the rhetoric used by the enunciators of the program of action, and more of a representation of the potential benefits than actual goals articulated by the actors. Therefore, the DCCA had to initiate the process of interessement to stabilize the problematization and demonstrate that the interest of the actors lies in accepting the proposed program of action, which was incorporating XBRL into the Danish financial reporting system.

It is also important to emphasize that unlike in Callon (1986) the outset of the key actors changed at the later stages of incorporating XBRL into the Danish financial reporting system. The translation process in this case turned out to be a process of mobilizing key actors later on, instead of having them defined at the stage of problematization.

\subsubsection{The process of interessement}

After defining the program of action and the key actors, the DCCA had to determine the solidity of the problematization in reality. This happened through the process of interessement, during which the regulatory agency initiated a group of actions in which it attempted to impose and stabilize the identity of the key actors it defined beforehand, and their roles in the translation process. In order to promote the idea of the new XBRL-based financial reporting practices, stabilize the identity of the predefined actors and emphasize the importance of cooperation in relation to creating the new system, the DCCA started dialogues with the key actors. The regulatory agency assumed that without the unanimous support of the key actors, the new financial reporting system would not prevail in the long run; therefore, the task of establishing an efficient communication channel with the actors seemed to be inevitable. For that reason, the DCCA decided to invite the spokespeople of the accounting professionals - representatives of large accounting firms, the FSR(Federation of Danish Auditors), smaller accounting firms and individual accounting professionals - and IT professionals who were involved in developing software for financial reporting purposes in Denmark, and start a dialogue with them regarding how to make sure that all parties benefited from introducing the XBRL-based financial reporting practices. In order to ensure that the dialogue would be efficient and productive in 2004 the DCCA decided to establish a national XBRL organization, XBRL Denmark, and appoint it as a platform for communicating with all the actors predefined during the process of problematization.

The DCCA did not want to force digitization and XBRL upon the actors within the financial reporting environment, thus the strategy the regulators decided to follow was based on engaging in a rhetoric that addressed the actors by emphasizing the benefits of XBRL thus achieving voluntary participation. Although it was expected that the business enterprises operating in Denmark would express resistance against voluntary digitization due to the associated costs demanded by the process of establishment, but convincing the firms about the importance of digitization through XBRL was 'easier than expected' according to a senior consultant at the Federation of Danish Auditors:

\footnotetext{
"At the early stages of the implementation, the firms only focused on the extra costs the XBRL-based financial reporting system might have been associated with. They expressed concern about the possibility of increasing prices of services provided by accountants. They [the business enterprises] just wanted to be sure that the new system would not impose too many extra costs upon them." (Senior consultant at the Federation of Danish Auditors)
}

These concerns were soothed after the DCCA successfully convinced the business enterprises about the long-term financial benefits of converting to XBRL. The DCCA argued that the implementation of the IT infrastructure that the XBRL-based financial reporting demanded would not only help the firms to increase the efficiency of their managerial accounting and analytical processes, but the new system would also allow them to reduce their financial reporting related expenses in the long run. Due to the rhetoric used by the DCCA, and the emergence of technological developments that carried the potential for improving their managerial accounting and analytical practices, such as XBRL itself; the business enterprises turned out to be in favor of the enunciators' plan.

Another important task of the regulatory agency was to make sure that the XBRL-based financial reporting system would actually be used - and thus made durable - once completed. According to the decision of the DCCA, the digitized financial reporting practices were intended to be used on a voluntary basis. This is why the regulators found it very important to: a) build a digitized system attractive enough for the accounting professionals to use voluntarily, and b) promote the possible benefits from the use of XBRL for accounting professionals during the translation process. As such, the accounting professionals were not expected to demonstrate active participation in the establishment of the digitized financial reporting system, but they were considered to be a key actor who needs to be prepared for the utilization of the new financial reporting practices. The rhetoric the DCCA used reflected this attitude: the regulators decided to approach the accounting professionals by emphasizing the benefits, they would be able to realize once the digitization was completed - instead of encouraging them to actively contribute towards the translation process. On the other hand, the IT professionals were approached with the request of active participation ever since the beginning of the problematization. The IT professionals demonstrated positive response to this request: they saw the potential of the plan through which they would be able to increase their IT related scientific knowledge and realize monetary profit at the same time. The alliance the DCCA started to form together with the IT professionals participating in the project assumed that together they would be able to deal with the possible resistance the accounting professionals might demonstrate during the translation process. As a representative of a participating IT company stated:

"We [the IT company and the DCCA] believed that upon completion, the XBRL-based system would have a positive effect on the quality of the annual reports prepared by smaller accounting firms, which would help convincing the accounting professionals about the benefits of digitization." (Representative of a participating IT company)

During the entire translation process, the DCCA played an active role in emphasizing the importance of cooperation between the key actors by arguing why and how a well-functioning XBRL-based financial reporting system would benefit them all. The inter definition of the actors and their roles, and the engagement in an active strategy of persuasion by the DCCA can be considered as the end of the stages of problematization and interessement in the translation process.

\subsection{The process of enrollment}

The process of interessement does not necessarily lead to the formulation of solid alliances therefore further mechanisms were needed to enroll the actors, and the enunciators defined during the problematization. For that reason, the DCCA needed to lay down the fundamentals of the program during the implementation process. The strategy was to emphasize the program of action, the role of XBRL as an obligatory passage point and the benefits from the technology. The DCCA needed to convince the actors participating in the translation process that XBRL could indeed be used to build the new, electronic financial reporting practices upon, and the new 
system would benefit the actors within the financial reporting environment. In order to build a convincing argument, the DCCA first had to further develop the existing IT infrastructure behind the Danish regulatory framework for financial reporting: the software solutions for preparing financial statements in XBRL format were rather underdeveloped at the beginning of the 2000s, furthermore, the regulators had to find a way to incorporate the Danish financial reporting taxonomy into XBRL. In order to tackle these issues, the DCCA decided to strengthen the alliance with - and as such, enroll the active participation of - IT professionals, and teamed up with a small accounting firm with a strong experience working with XML. As one of the project leaders at the DCCA expressed:

"Before 2002 they [the IT firm] had succeeded in carrying out rather difficult tasks and working successfully with both EDIFACT and XML and they expressed high interest in looking into how it would be possible to work with XBRL." (Project manager at DCCA)

The alliance was formed with high hopes, but getting the IT infrastructure and the Danish regulatory framework for financial reporting ready for the introduction of XBRL turned out to be more difficult than expected. The first plan was to make the Danish financial reporting taxonomy in XBRL format work in the accounting software, CaseWare, and to provide for the larger enterprises regarding financial reporting purposes, while for the smaller companies, an online, web-based solution was intended to be developed. The first version of the system was launched in 2005 , but the provided IT solutions contained serious errors: the biggest problems occurred due to the undeveloped platform and the dissatisfactory incorporation of the Danish financial reporting taxonomy into the XBRL standard. Instead of full accounting coverage, the IT platform could only include the main figures from the accounts. A representative of one of the accounting firms stated:

"Basic things such as making a list of daughter companies were not feasible using the provided system, due to technical difficulties." (Accounting firm representative)

Due to the shortcomings of the system, there was still a need for paper documents to supplement the financial reporting. A second attempt was made in 2008 to implement the technological development but the provided system once again turned out to be dissatisfactory as a solid foundation for such a large-scale use.

In 2010, the DCCA realized the need to involve more members from the IT community in order to be able to build a sturdy financial reporting system based on XBRL. Some of the best experts and IT firms around the world were contacted to help develop an XBRL taxonomy based on best practices that would be compatible with the Danish regulatory framework for financial reporting. A partner in one of the IT firms joining the project in 2010 stated:

"We, software developers, saw a huge potential in joining the DCCA and helping them introduce XBRL into the Danish financial reporting scene. We assumed that once it [XBRL] is out there the focus would change to the user side, and we could start developing and providing software for the market that helps investors, creditors and analysts processing the available XBRL data." (Partner in one of the involved IT firms)

The large scale national and international cooperation turned out to be fruitful and eventually led to overcoming the IT-related difficulties by 2011 .

In parallel with building an alliance with the IT professionals, the DCCA had to initiate the enrollment of another actor, the group of accounting professionals, as well. The first attempts at enrolling the accounting professionals followed the strategy of promoting the benefits of XBRL. According to the plans of the regulatory agency, the new practices would have been based on a voluntary basis, therefore, convincing the prepares and the auditor of the financial statements to actually use the new system was considered to be highly important. The large accounting firms showed interest in the technology since the first plans emerged, but the smaller firms and the individual accounting professionals seemed to be uninterested in using XBRL on a voluntary basis. As a representative of a number of smaller auditor firms pointed out:

"Some of the smaller auditor companies used to do their practices in a very conservative way for many years, and they were convinced that their practices were better, and they were more right than the regulatory authorities. Voluntary compliance was therefore, out of the question." (Representative of smaller Danish auditor firms)

At this point, an actor who was previously considered to be homogeneous concerning their role during the translation turned out to be distinguishable into two groups depending on their relation to the program of action. The accounting professionals representing large accounting firms did not, while the accounting professionals representing smaller accounting firms and the individual accountants did demonstrate resistance against the program of action.

The chances of establishing the XBRL-based financial reporting system that would be used by all accounting professionals voluntarily got slimmer when it became obvious that solving the IT-related problems would require a much longer time than the developers of the system had anticipated. As already mentioned, the first two attempts to introduce the technology failed due to serious IT related flaws, which certainly did not help the regulatory agency to convince the potential users to convert to the system voluntarily. The DCCA was aware of this as well shortly after the introduction of the first version of the digitized financial reporting practices in 2005: the program of action had to face the resistance of the accounting professionals, as the regulatory agency did not receive a single annual report in XBRL format. The electronic platform provided by the DCCA was not even complete enough to convince the larger accounting firms, who would otherwise be in favor of XBRLbased financial reporting. The resistance demonstrated by the potential users became so strong that the idea of convincing the accounting professionals to use the digitized system voluntarily did not seem to be possible. As one of the leaders of the project at the DCCA stated:
"At one point, I came to realize that there was no way we were going to get anybody to file anything in XBRL format, unless we made it mandatory. The head of the project at that time insisted that we would have to build the system and make sure it worked by operating it on a voluntary basis for at least a couple of years before making it mandatory. Then I told him that we could probably make it technically feasible, but no one would file the annual reports in XBRL format if it was not mandatory." (Project leader at DCCA)

To overcome this resistance, the DCCA decided to change its strategy in 2010: besides engaging in large-scale cooperation with the IT community to make sure that the IT-related problems would be eliminated; the regulatory agency decided to make the new XBRLbased financial reporting system mandatory. In order to be able to enforce mandatory compliance the DCCA had to introduce one more actor - to those who had been interred defined during the problematization - the political leaders into the translation process. As one of the project leaders at the DCCA expressed:

"The political leaders had the power to change the legislative framework of the Danish financial reporting environment by making the new system required by law and as such help us deal with the resistance demonstrated by the auditors." (Project leader at DCCA)

The enrollment of the political leaders happened smoothly: the Danish politicians had expressed, even before implementing mandatory digital financial reporting, a high level of interest in making all communications between the citizens and government digital, 
and took actions to create the infrastructure for the transition from analogue to digital communication. The ongoing financial crisis of 2007-2008 turned out to be an important accelerator of the process as well: the stakeholders of the Danish financial reporting environment considered technological developments as means for preventing future financial crises. The politicians were in favor of the idea of mandatory reporting in XBRL format and stated that as soon as the DCCA makes sure the IT infrastructure is ready the new financial reporting practices would become required by law. According to a project leader at the DCCA:

"It was not really a political issue; the case received full support from all the parties. Not even the left-wing parties were against the proposal, even though it was a right-wing government proposing the law." (Project leader at DCCA)

As such, the resistance demonstrated by the accounting professionals and the ambition of the political leaders to establish digital communication between the state, and the citizens created a temporary outcome in which the DCCA mobilized a key actor who was not interred defined in the original problematization. The mobilization of political power contributed to the shift in enrolling the accounting professionals: the initial strategy of persuasion turned into a strategy of force. The enrollment of the accounting professionals can in this case also be considered as a mark of the end of the enrollment process: at this point, all the keys actors predefined by the DCCA during the problematization were enrolled in the translation process.

\subsection{The process of mobilization}

Turning the enrollment into support from the representatives of the actors was a crucial part of the incorporation of XBRL into the Danish financial reporting environment, if the project was to succeed in the long run. For this reason, the DCCA had to identify the spokespeople of the actors and engage in efficient communication with them to render the entities mobile and make them actively contribute towards the process of introducing the XBRL-based financial reporting practices. In this case, mobilization cannot be clearly separated from enrollment as some elements of the two processes were ongoing simultaneously: the establishment of XBRL Denmark, the communication platform assembling the key actors happened already in 2004, and the mobilization of certain actors, such as the IT professionals and the political leaders commenced at earlier stages of the translation process. As the previous section illustrated, the mobilization of political power was considered to be a necessary step by the regulatory agency, but it also created tension between the DCCA and the group of accounting professionals. The declaration of the new financial reporting practices now required by law clearly divided the accounting professionals: the larger accounting firms were in favor, while the smaller accounting firms and individual accounting professionals were against the mandatory compliance. The larger accounting and auditing firms quickly realized the opportunities in the mandatory utilization of XBRL. As a representative of one of the Big Four accounting firms stated:

"In our firm for several years, we had to work with different templates and annual reports prepared by hundreds of partners with their own impression of what an annual report should look like. The introduction of the mandatory use of this technological development was considered to make it possible for us to say that there is the XBRL taxonomy we have to follow, so this is the way we do it. Large auditing firms like us also had to make an investment, but we knew that the electronic standardization of the annual reports would make our practices more efficient than they were before." (Representative of one of the Big Four accounting firms)

A representative of another one of the Big Four accounting firms added:
"In our firm, we would use the XBRL technology to monitor the quality of our reports on financial statements. The utilization of an electronic standard turned out to be a very efficient tool to monitor the way we are working in our firm. Instead of having a small sample, we could start monitoring 12,000 financial statements, which made it much easier to see the bad or incorrect things." (Representative of another one of the Big Four accounting firms)

One the other hand, the general opinion of the individual accountants and auditors working in smaller firms was not in favor, to say the least, of the technology when it became declared that the use of XBRL would be mandatory. As a representative of a number of smaller accounting firms stated:

\begin{abstract}
"At the start, the professionals working in small accounting and auditing firms did not like the idea of mandatory compliance at all. They thought that their practices were good enough. Therefore, the introduction of a technological change would be unnecessary. In their opinion the new system, due to the utilization of advanced IT solutions, would only mean additional costs, more complex and more difficult bookkeeping and auditing practices." (Representative of smaller Danish auditor firms)
\end{abstract}

XBRL Denmark, the national XBRL organization established at the early stage of the translation process, played an important role in dissolving this tension after the mandatory use of XBRL was announced. The regular meetings assembling the representatives of all the actors through XBRL Denmark turned out to be an important factor in fore going to the further development of the resistance demonstrated by the accounting professionals representing smaller firms, thus contributing to the successful incorporation of the technology. As a project manager at the DCCA stated:

\begin{abstract}
"Things are being moved to another level if there is a platform where the most important actors, such as the vendors, the regulators and the auditors have the possibility to discuss the emerging issues in person. XBRL Denmark created new paths of communication between the participating actors who made the whole domain move forward faster and with better quality. The existence of regular personal meetings changed the entire way in which the stakeholders of the financial accounting environment work together." (Project leader at DCCA)
\end{abstract}

The existence and efficiency of XBRL Denmark ensured the representatives of smaller accounting firms and individual accountants that their opinion would be heard, and they would have the possibility to influence the decisions concerning the introduction of the mandatory XBRL-based financial reporting system. At the meetings of the XBRL Denmark, the DCCA acted as the legitimate spokesperson for the Danish financial reporting system, and followed the strategy of emphasizing how the incorporation of XBRL into the financial reporting environment would benefit all the participating actors. By 2010, it had become evident that the introduction of the new system would imply significant changes in the financial reporting practices, especially in relation to the surveillance of the disclosed financial data: the combination of XBRL and the developed IT platform would enable the analysis of all the submitted annual reports instead of having to be restricted to random sampling, and the analysis of the data would demand fewer resources such as time and money. These changes were considered by all the participating actors to contribute positively to maintain the regulatory framework for financial reporting in a stable and sustainable way in the long run, although some aspects of the yet to be implemented - and by that time declared mandatory - systems were awaiting for further adjustments in order to sooth the emerging resistance through a series of negotiations between the actors. One of the issues that generated resistance among the accounting professionals was the associated costs the preparers of the financial statements would need to pay due to the conversion, and the timing of 
the implementation of the new system. The representatives of the accounting professionals argued that converting to the new financial reporting practices could turn out to be rather costly. Especially the smaller accounting firms and the individual accounting professionals were concerned about the costs of adopting the digital bookkeeping and financial reporting, therefore they demanded the development of an IT solution that was free of charge and covered at least reporting class B enterprises. One of the project managers at the DCCA stated:

"This led to complications during the development of the system, as the auditors' demands made the further extension of the taxonomy inevitable, thus making the platform more and more complexes." (Project manager at DCCA)

The emerging resistance demonstrated by the accounting professionals demanded further negotiations between the DCCA and representatives of the IT professionals. The outcome of this negotiation was the development of a free of charge web-based solution, called 'Regnskab Basis which', could be used for generating annual statements of smaller enterprises in XBRL format. The larger firms were obliged to use XBRL-software for generating their annual statements and use a different online platform - Regnskab Special - for submitting accounts, such as cash flow statements or entire consolidated financial statements, which did not fit into the basic solution because of their advanced complexity. The provided web-based solution also assisted in soothing a potentially present source of resistance by simplifying the use of the XBRL-based bookkeeping system. As are presentative of one of the Big Four accounting firms stated:

The ordinary auditors do not have to know much about XBRL. Most of them only know that they need to file the annual reports in digital format, but the software does the job of creating the annual reports in XBRL-format. (Representative of one of the Big Four accounting firms)

The large firms - business enterprises falling under reporting class $\mathrm{C}$ and $\mathrm{D}$ - and the auditors representing them argued that converting to the XBRL-based financial reporting system would demand significant effort from larger firms. Therefore, they would need more time to get ready for filing their annual reports in XBRL-format. By ignoring these concerns the DCCA would have risked the emergence of yet another source of resistance. In order to handle this issue the DCCA engaged in a series of negotiations with the accounting professionals - especially the spokespeople of the larger accounting firms and professionals representing larger companies after which the regulatory agency decided to give more time for enterprises falling under reporting classes $\mathrm{C}$ and $\mathrm{D}$ to comply with the new system. Table 1 illustrates the reporting classes of the business entities operating in Denmark and the date of obligatory conversion to reporting in XBRL format.

\begin{tabular}{|c|c|c|c|c|}
\hline Reporting classes & $\begin{array}{l}\text { Balance sheet } \\
\text { total (in DKK) }\end{array}$ & $\begin{array}{l}\text { Revenue (in } \\
\text { DKK) }\end{array}$ & $\begin{array}{l}\text { Number of } \\
\text { employees }\end{array}$ & $\begin{array}{l}\text { XBRL obligatory for the } \\
\text { fiscal year with a } \\
\text { balance date of }\end{array}$ \\
\hline A (very small enterprises) & 0-7 million & 0-12 million & $0-10$ & - \\
\hline B (small enterprises) & 0-36 million & 0-72 million & $0-50$ & June $30^{\text {th, }} 2012$ or later \\
\hline $\begin{array}{l}\mathbf{C} \text { (medium-sized } \\
\text { enterprises) }\end{array}$ & 36-143 million & 72-286 million & $50-250$ & $\begin{array}{l}\text { December } 31^{\text {st }}, 2012 \text { or } \\
\text { later }\end{array}$ \\
\hline C (large enterprises) & Over 143 million & $\begin{array}{l}\text { Over } 286 \\
\text { million }\end{array}$ & Over 250 & $\begin{array}{l}\text { December } 31^{\text {st }}, 2012 \text { or } \\
\text { later }\end{array}$ \\
\hline $\begin{array}{l}\text { D (listed and all state- } \\
\text { owned enterprises) }\end{array}$ & - & - & - & $\begin{array}{l}\text { December } 31^{\text {st }}, 2013 \text { or } \\
\text { later }\end{array}$ \\
\hline
\end{tabular}

Table 1: Financial Reporting Classes of Businesses in Denmark and the Date of Obligatory Conversion to Reporting in XBRL Format

The reason behind the strategy of gradual introduction of the new financial reporting practices was that it was considered to be easier for the smaller firms to report in XBRL due to their simpler accounting, compared to the larger companies, and the use of Regnskab Basis. Furthermore, firms falling under reporting classes $\mathrm{C}$ and $\mathrm{D}$ were provided the possibility to use Regnskab Special on a voluntary basis before compliance with the new system became obligatory for them. As a project manager at the DCCA expressed:

"The strategy of gradually introducing the new system on a mandatory basis turned out to be one of the most important factors of successfully incorporating XBRL into the Danish financial reporting scene. It was beneficial for both the DCCA and the auditors, and eventually contributed towards the maintenance and further development of the system." (Project manager at DCCA)

As the IT infrastructure was created and the financial reporting environment was made aware of the mandatory use of XBRL, on April 7 $7^{\text {th }}, 2011$ the Danish Parliament, after amending the Danish Financial Statement Act, passed a law regarding mandatory digital financial reporting in Denmark. The transmission from the old system and the incorporation of XBRL into the financial accounting practices did not happen without any complications, but the new system has endured and by 2014 the larger - class C and class D - companies operating in the Danish financial reporting jurisdiction had converted to the use of XBRL as well.

\section{Concluding discussion}

The purpose of this paper was to analyze how XBRL was incorporated into a specific financial reporting environment. Therefore, the following research question was posed how does XBRL get incorporated into the financial reporting environment of a country? The research question was answered by illustrating how the Danish regulatory agency for financial reporting, the DCCA, initiated a translation process to incorporate XBRL into the Danish financial reporting system in accordance with its ambition to digitize the financial reporting practices in Denmark. The exploration of the translation process through which XBRL got embedded into the financial reporting environment enabled the illustration of how the emerging resistance demonstrated by various actors shapes the incorporation process.

The paper offers three contributions to the extant literature: first, it adds to the XBRL literature by showing how XBRL is incorporated into the financial reporting system of a country. Secondly, it adds to the financial reporting literature by illustrating how resistance shapes the introduction of certain changes within the financial reporting environment, and how regulators deal with resistance 
demonstrated by the actors within the financial reporting environment when introducing complex changes, such as XBRL. Thirdly, the paper adds to the ANT literature - especially those based on Callon's translation model - by illustrating how the emerging resistance creates certain situations in which the actors need to reconsider their strategies during the process of translation.

\subsection{The process of incorporating XBRL into a financial reporting system}

Although the subjects of utilizing XBRL within organizational settings or the qualitative characteristics of XBRL have attracted a considerable amount of scholarly attention (e.g. Bartley et al. 2011, Cohen et al .2014, Debreceny et al. 2011, Doolin 2007, Henderson et al. 2012, Plumlee 2008, Srivastava 2010), empirical research focusing on the process of introducing XBRL into the financial reporting practices is rare within the literature. The purpose of this paper was to address this gap in the literature by taking an ANT approach and applying the translation model developed by Michel Callon (1986) to the case of incorporating XBRL into the Danish financial reporting environment. The analysis of the collected empirical data showed that making XBRL part of an existing financial reporting regulatory framework, thus achieving digitization, demands significant effort from the regulators - just like in an organizational setting, as illustrated by Doolin and Troshani (2007), and Bartley et al.(2011). The incorporation process requires strategic steps taken in order to successfully weave XBRL together with the national financial reporting taxonomy, and to develop the overall IT infrastructure behind the digitized financial reporting system. These strategic steps call for the formulation of an efficient alliance between the regulators and IT professionals possessing adequate expertise and knowledge about XBRL and XML. In this case, the IT-related resistance delaying the project was not resolved until the DCCA induced a large-scale cooperation, including international experts with strong experience in the utilization of XBRL. Thus, this paper illustrated how the changing dynamics of the translation invites new actors into the process. In this case, the presence of XBRL created a dynamic in which the core of the technology, the electronic language itself, was given and remained constant, but supplementary actors needed to be mobilized in order for the XBRL to be incorporated.

During the translation, the role of XBRL also underwent change. At the early stages of the project XBRL was not declared as the obligatory passage point but after the DCCA was convinced that it could be the key of digitization, XBRL was presented to the actors defined during the problematization as the obligatory passage point to the translation. Although the DCCA attempted to create a unified image of XBRL at the early stages of the project - mainly by advocating the benefits, the XBRL-based digitization would provide for all the actors within the financial reporting environment - the perception of the actors about the role and meaning of XBRL went through a transformation during the translation process. During the period of problematization, the DCCA had an assumption about how XBRL would be perceived by the actors and aligned its strategy and rhetoric accordingly. Although, as it became obvious as the translation progressed, the perception of the actors was not always aligned with the original problematization proposed by the DCCA. These misalignments led to the emergence of resistance, which made the DCCA reconsider its strategic steps to be taken.

Another important contribution of this paper to the literature is the illustration of how XBRL shapes the environment it is incorporated into. At the beginning of the translation process, XBRL created confusion among some of the key actors because the environment the technology was introduced into functioned more like a setting than a context in which XBRL can be fully understood and assessed by the participating actors. The DCCA and the IT professionals did not know how the existing IT infrastructure should be developed, and a large proportion of the accounting professionals did not know why converting to the use of XBRL was necessary or beneficial. In order to address this uncertainty, the actors had to assess and understand the changes that XBRL would entail in the original setting of the financial reporting environment. This enabled the actors to articulate their interests in the changing environment and take strategic steps accordingly.

\subsection{The role of resistance in shaping regulatory decisions in relation financial reporting}

Extant literature on the subject of resistance to regulatory changes provided by Laffont and Tirole (1993), Peltzman (1976), Stigler (1971), or Watts and Zimmerman (1978) illustrates the behavior of the actors within a regulatory environment based on their interests and preferences. The regulatory settings described in these studies suggest that the actors express rational behavior, and they are aware of their preferences before taking a strategic step in relation to the change in the regulatory environment. In such settings, the interests and preferences remain stable and consistent throughout the process of change. This paper, on the other hand, explored a case in which some of the actors were hesitant, as their interests in relation to the proposed change, the utilization of XBRL, were not clear. The majority of studies illustrating struggles and conflicts over interests assumed that the participating actors have well defined interests and preferences (Baudot \& Walton 2014), but in this case, the process of interessement revealed that actors in relation to a particular object, like XBRL, may not always be aware of, or able to predict, their preferences. The initiation of the translation process introduced uncertainty for some of the accounting professionals at the beginning: they did not know why the conversion to XBRL was needed, and whether it would really contribute to the development of the financial reporting practices. At the stage of appointing XBRL as the obligatory passage point of the translation process the DCCA was the only actor aware of their own interests. The regulatory agency argued that the digitization established by the incorporation of XBRL into the financial reporting environment would be beneficial for all the participating actors and took strategic steps accordingly. While the DCCA based its argumentation on academic research, the accounting profession approached the planned changes from a practical sense, which - without understanding and accepting the reasons of incorporating XBRL - led to resistance and project stagnation. In case the interests are known at the beginning, the layout of the change in the regulatory environment can be static and predictable, but the illustration of the translation process in this paper showed that the formulation of interests and preferences are fluid, the translation process can induce uncertainty and only at the end of the process - after the context has been constructed - can the actors know what their expected benefits and interests might have been.

The uncertainty introduced by the translation process itself emphasizes the importance of selecting the appropriate tools to enroll the key actors in case of initiating complex regulatory changes within the financial reporting environment. In this case, achieving voluntary acceptance of the changes proposed by financial reporting regulators turned out to be impossible: the DCCA did not manage to enroll the entire accounting profession voluntarily; therefore, the regulators needed to change strategy and mobilize political power. Overcoming resistance by shifting the initial strategy of persuasion into a strategy of force to this case turned out to be a necessary step of making progress through the translation process. Furthermore, the announcement of the mandatory use of XBRL initiated an efficient communication between the DCCA and the accounting professionals demonstrating resistance against the incorporation of XBRL into the Danish financial reporting practices.

Furthermore, the paper showed that although research suggests that the establishment of XBRL demands significant effort at the organizational level (Bartley et al. 2011, Doolin \& Troshani 2007) the business enterprises operating within the Danish financial reporting environment did not demonstrate significant resistance against the planned regulatory changes. The possible associated costs, such as training the accounting personnel and establishing necessary IT infrastructure, did raise some concern among the managers of the business enterprises, but those did not eventually exceed the managers' expected benefits of the utilization of XBRL. 


\subsection{ANT and the translation model}

Examples of the application of the translation model within accounting research have been provided by studies such as Becker et al. (2014), Briers and Chua (2001), Miller (1991), Preston et al. (1992), or Robson (1991). One of the purposes of this paper has been to add to the above literature and explore how the original program of action articulated by the enunciator of the translation went through a transformation due to the emerging resistance during the translation. The paper shows that the translation process itself is a series of responses given by the enunciator - and the alliances formulated by it - to the resistance demonstrated by actors within the environment where the change is intended to occur. The 'interaction between heterogeneous actors described by accounting studies based on the translation model (e.g. Miller 1991,Preston et al.1992) is in fact the enunciator's intention to cause change and the reactions given by other actors to prevent change. This train of thought leads directly back to why the word 'incorporation' was used in the research question of this paper instead of concepts such as 'implementation' or 'adaptation': the case of incorporating XBRL into the Danish financial reporting system shows that the incorporation process is neither implementation, nor adaptation, but indeed translation of a certain technology.

The role of resistance also highlights the importance of forging alliances in order for the enunciator to be able to provide appropriate responses to the emerging resistance. In the case explored in this paper, the key players at the outset were not established during the problematization, and unlike in Callon (1986) it changed over time: the accounting professionals were considered homogeneous concerning their role during the translation, but along the way they turned out to be two groups depending on their relation to the program of action: the accounting professionals representing smaller accounting firms and the individual accountants demonstrated resistance against the program of action, unlike the accounting professionals within larger firms. Furthermore, the process of translation in this case turned out to be a process of finding and involving key actors, instead of having them defined at the earlier stages of the process. The political leaders were not considered to be a key actor until the DCCA realized that the enrollment of all the accounting professionals would not happen on a voluntary basis. The enrollment and mobilization of the political leaders changed the outset of the original problematization, and helped create a context in which the translation became feasible. The paper thus illustrates how difficult it is to identify the key actors at the stage of problematization: new actors can turn up and enroll in the translation as time progresses. In such a setting, where the temporary outcomes of the translation are difficult to predict the enunciator has to reconsider the goals and interests assumed at problematization. The translation thus becomes a process of discovering: a) new interests that can be aligned with the participating actors in order to convince them, and b) actors that had not been involved in the problematization but would be interested in joining the translation. The discovery of interests and the involvement of interested parties further contributed towards the transformation of the technological and professional settings of the financial reporting environment into a context in which XBRL is understood, accepted, and therefore, capable of functioning. Without this transformation the incorporation of the technology would neither have been possible, nor reasonable.

\section{Acknowledgments}

The author of this paper would like to thank Jan Mouritsen, Søren Sommer Jagd, Peter Skærbæk, and an anonymous reviewer for their helpful comments. Previous versions of the paper have been presented at the research group meetings of the Management and Organization research group at the Department of Social Sciences and Business, Roskilde University.

\section{References}

[1] Alles M \& Piechocki M (2010) Will XBRL improve corporate governance? A framework for enhancing governance decision making using interactive data. International Journal of Accounting Information Systems 13, 91-108. https://doi.org/10.1016/j.accinf.2010.09.008

[2] Baldwin AA, Brown CE \& Trinkle, BS (2006) XBRL: An impacts framework and research challenge. Journal of Emerging Technologies in Accounting 3, 97-116. https://doi.org/10.2308/jeta.2006.3.1.97.

[3] Bartley J, Chen AYS \& Taylor EZ (2011) A comparison of XBRL filings to corporate 10-Ks - Evidence from the voluntary filing program. Accounting Horizons 25, 227-245. https://doi.org/10.2308/acch-10028.

[4] Baudot L \& Walton P (2014) Influences on the standard-setting and regulatory process. In The Routledge companion to accounting, reporting and regulation (van Mourik C \& Walton P eds.), Routledge, Abingdon, UK, pp. 318-338.

[5] Becker SD, Jagalla T \& Skærbæk P (2014) The translation of accrual accounting and budgeting and the reconfiguration of public sector accountants' identities. Critical Perspectives on Accounting 25, 324 338. https://doi.org/10.1016/j.cpa.2013.05.004.

[6] Branson M (2002) Using XBRL for data reporting. Statistical Journal of the UN Economic Commission for Europe 19, 201-204.

[7] Briers M \& Chua WF (2001) the role of actor-networks and boundary objects in management accounting change: A field study of implementation of activity-based costing. Accounting, Organizations and Society 26, 237-269. https://doi.org/10.1016/S03613682(00)00029-5.

[8] Callon M (1986) Some elements of sociology of translation: Domestication of the scallops and the fishermen of St Brieuc Bay. In Power, action and belief: A new sociology of knowledge? (Law $\mathrm{J}$ ed.) Routledge \& Kegan Paul, London, UK, pp. 196-223.

[9] Callon M \& Latour B (1981) Unscrewing the big Leviathan: How actors macro-structure reality and how sociologists help them to do so. In Advances in social theory and methodology: Towards an integration of micro- and macro-sociologies (Knorr-Cetina K \& Cicourel AV eds.), Routledge \& Kegan Paul, London, UK, pp. 277-303.

[10] Chang C \& Jarvenpaa S (2005) Pace of information systems standards development and implementation: The case of XBRL. Electronic $\quad$ Markets 15, 365-377. https://doi.org/10.1080/10196780500303029.

[11] Chen YC (2012) A comparative study of e-government XBRL implementations: The potential of improving information transparency and efficiency. Government Information Quarterly 29, 553-563. https://doi.org/10.1016/j.giq.2012.05.009.

[12] Chowdhuri R, Yoon VY, Redmond R T \& Etudo UO (2014) Ontology based integration of XBRL filings for financial decision making. $\begin{array}{llll}\text { Decision } & \text { Support } & \text { Systems } & 68,76 .\end{array}$ https://doi.org/10.1016/j.dss.2014.09.004.

[13] Cohen EE, Debreceny R, Farewell S \& Roohani S (2014) Issues with the communication and integrity of audit reports when financial reporting shifts to an information-centric paradigm. International Journal of Accounting Information Systems 15, 400-422. https://doi.org/10.1016/j.accinf.2014.05.008.

[14] Debreceny RS, Farewell SM, Piechocki M, Felden C, Gräning A \& d'Eri A (2011) Flex or break? Extensions in XBRL disclosures to the SEC. Accounting Horizons 25, 631-657. https://doi.org/10.2308/acch-50068.

[15] Doolin \& Troshani I (2007) Organizational adoption of XBRL. Electronic $\quad$ Markets 17, 199-209. https://doi.org/10.1080/10196780701503195.

[16] Downs, A (1957) An Economic Theory of Democracy. Harper, New York.

[17] Efendi J, Park JD \& Smith LM (2014) Do XBRL filings enhance informational efficiency? Early evidence from post-earnings announcement drift. Journal of Business Research 67, 1099-1105. https://doi.org/10.1016/j.jbusres.2013.05.051.

[18] Fogarty TJ, Hussein M, \& Ketz JE (1994) Political aspects of financial accounting standard setting in the USA. Accounting, Auditing \& Accountability Journal 7, 24-46. https://doi.org/10.1108/09513579410069830.

[19] Georgiou G(2002) Corporate non-participation in the ASB standardsetting process. European Accounting Review 11, 699-722. https://doi.org/10.1080/0963818022000001028.

[20] Gray GL \& Miller DW (2009) XBRL: Solving real-world problems. International Journal of Disclosure \& Governance 6, 207-223. https://doi.org/10.1057/jdg.2009.8. 
[21] Henderson D, Sheetz SD \& Trinkle BS (2012) The determinants of inter-organizational and internal in-house adoption of XBRL: A structural equation model. International Journal of Accounting Information Systems 13, 109-140. https://doi.org/10.1016/j.accinf.2012.02.001.

[22] Henriksen K (2001) E-regnskaber åbner ny verden. Dagbladet Børsen. Available at: http://borsen.dk/nyheder/avisen/artikel/12/578157/artikel.html (accessed 3 April 2016)

[23] Hill NT, Shelton WS \& Stevens KT (2002) Corporate lobbying behavior on accounting for stock-based compensation: Venue and format choice. Abacus 38, 78-89. https://doi.org/10.1111/1467$\underline{6281.00098}$.

[24] Hoffmann S \& Zülch H (2014) Lobbying on accounting standard setting in the parliamentary environment of Germany. Critical Perspec$\begin{array}{llll}\text { tives on } & \text { Accounting } & \text { 709-723 }\end{array}$ https://doi.org/10.1016/j.cpa.2014.04.003.

[25] Horn U (2004) Digitale regnskaber giver besparelser. Dagbladet Børsen. Available at: http://borsen.dk/nyheder/avisen/artikel/12/1367969/artikel.html (accessed 3 April 2016)

[26] Hudson L \& Ozanne J (1988) Alternative ways of seeking knowledge in consumer research. Journal of Consumer Research 14, 508-521. https://doi.org/10.1086/209132.

[27] Jeppesen KK (2010) Strategies for dealing with standard-setting resistance. Accounting, Auditing\& Accountability Journal 23,175-200. https://doi.org/10.1108/09513571011023183.

[28] Jorissen A, Lybaert N, Orens R \& van der Tas L (2012) Formal participation in the IASB's due process of standard setting: A multi-issue/multi-period analysis. European Accounting Review 21, $693-$ 729. https://doi.org/10.1080/09638180.2010.522775.

[29] Jönsson S. (1994) Changing accounting regulatory structures in the context of a strong state. Critical Perspectives on Accounting 5, 341360. https://doi.org/10.1006/cpac.1994.1021.

[30] Justesen L \& Mouritsen J (2011) Effects of actor-network theory in accounting research. Accounting, Auditing \& Accountability Journal 24, 161-193. https://doi.org/10.1108/09513571111100672.

[31] Kelly L (1982) Corporate lobbying and changes in financing or operating activities in reaction to FAS No. 8. Journal of Accounting and Public Policy 1, 153-173. https://doi.org/10.1016/S02784254(82)80005-7.

[32] Kelly L (1985) Corporate management lobbying on FAS No.8: Some further evidence. Journal of Accounting Research 23, 619-632. https://doi.org/10.2307/2490829.

[33] Kenny SY \& Larson RK (1993) Lobbying behaviour and the development of international accounting standards. European Accounting Review 2, 531-554. https://doi.org/10.1080/09638189300000050.

[34] Laffont JJ \& Tirole J (1993) A theory of incentives in procurement and regulation. The MIT Press, Cambridge, Massachusetts.

[35] Latour B (1991) Technology is society made durable. In A sociology of monsters: Essays on power, technology and domination (Law J ed.), Routledge, London, UK, pp. 103-131.

[36] Liu C, Luo XR, Sia CL, O'Farrell G \& Teo HH (2014) The impact of XBRL adoption in PR China. Decision Support Systems 59, 242 249. https://doi.org/10.1016/j.dss.2013.12.003.

[37] Liu C, Wang T \& Yao, LJ (2014) XBRL's impact on analyst forecast behavior: An empirical study. Journal of Accounting and Public Policy 33, 69-82. https://doi.org/10.1016/j.jaccpubpol.2013.10.004.

[38] Malsch B \& Gendron Y (2011) Reining in auditors: On the dynamics of power surrounding an 'innovation' in the regulatory space. Accounting, Organizations and Society 36, 456-476. https://doi.org/10.1016/j.aos.2011.06.001.

[39] Miller P (1991) Accounting innovation beyond the enterprise: Problematizing investment decisions and programming economic growth in the UK in the 1960s. Accounting, Organizations and Society 16, 733-762. https://doi.org/10.1016/0361-3682(91)90022-7.

[40] Müller-Wickop N, Schultz M \& Nüttgens M (2012) XBRL: Impacts, issues and future research directions. In Enterprise Applications and Services in the Finance Industry (Rabhi FA \& Gomber P eds.), Springer, Berlin, pp. 112-130.

[41] Peltzman S (1976) Toward a more general theory of regulation. Journal of Law and Economics 19, 211-240. https://doi.org/10.1086/466865.

[42] Plumlee D \& Plumlee M (2008) Assurance on XBRL for financial reporting. Accounting Horizons 22, 353-368. https://doi.org/10.2308/acch.2008.22.3.353

[43] Power M (1993) The politics of financial auditing. The Political Quarterly 64, 272-284. https://doi.org/10.1111/j.1467923X.1993.tb00344.x.

[44] Preston AM, Cooper DJ \& Coombs RW (1992) Fabricating budgets: A study of the production of management budgeting in the National
Health Service. Accounting, Organizations and Society 17, 561-593. https://doi.org/10.1016/0361-3682(92)90014-J.

[45] Robson K (1991) on the arenas of accounting change: The process of translation. Accounting, Organizations and Society 16, 547-570. https://doi.org/10.1016/0361-3682(91)90041-C.

[46] Robson K (1992) Accounting numbers as 'inscription': Action at a distance and the development of accounting. Accounting, Organizations and Society 17, 685-708. https://doi.org/10.1016/03613682(92)90019-O.

[47] Sikka P (2002) The politics of restructuring the standard setting bodies: The case of the UK's auditing practices board. Accounting Forum 26, 97-125. https://doi.org/10.1111/1467-6303.t01-1-00010.

[48] Srivastava RP, \& Kogan, A (2010) Assurance on XBRL instance document: A conceptual framework of assertions. International Journal of Accounting Information Systems 11, 261-273. https://doi.org/10.1016/j.accinf.2010.07.019.

[49] Stigler GJ (1971) The theory of economic regulation. The Bell Journal of Economics and Management Science 2, 3-21. https://doi.org/10.2307/3003160.

[50] Sutton TG (1984) Lobbying of accounting standard-setting bodies in the U.K. and the U.S.A.: A Downsian analysis. Accounting, Organizations and Society 9, 81-95. https://doi.org/10.1016/03613682(84)90031-X.

[51] Troshani I \& Lymer A (2010) Translation in XBRL standardization. Information Technology \& People 23, 136-164. https://doi.org/10.1108/09593841011052147.

[52] Troshani I, Rampersad G \& Plewa C (2011) Adopting innovation management software in university innovation commercialization. Journal of Computer Information Systems 52, 83-92.

[53] Venkatesh R \& Armitage J (2012) Accountants' awareness and perceptions about assurance on XBRL financial statements. Journal of Applied Business Research 28, $145 \quad$ - 154. https://doi.org/10.19030/jabr.v28i2.6838.

[54] Watts RL \& Zimmerman JL (1978) Towards a positive theory of the determination of accounting standards. The Accounting Review 53, $112-134$.

[55] Zhu H \& Wu H (2014) Assessing the quality of large-scale data standards: A case of XBRL GAAP taxonomy. Decision Support Systems 59, 351-360. https://doi.org/10.1016/j.dss.2014.01.006. 